\title{
PREDICTION OF SHORT-TERM PERINATAL OUTCOME IN OLIGOHYDRAMNIOS AT TERM- ROLE OF UMBILICAL CORD ARTERIAL BLOOD LACTATE LEVELS
}

\author{
Amera Tariq, Afeera Afsheen*, Bushra Iftikhar, Rabiah Anwar, Rizwana Bashir Kiani, Saira Mahboob \\ PNS Shifa Karachi Pakistan, *Combined Military Hospital Multan/National Institute of Medical Sciences (NUMS) Pakistan
}

\section{ABSTRACT}

Objective: Investigating the perinatal outcome in pregnant patients with oligohydramnios at term.

Study Design: Prospective observational study.

Place and Duration of Study: Department of Obstetrics and Gynaecology, Pakistan Naval Ship (PNS) Shifa Hospital Karachi, from Mar to Oct 2020.

Methodology: The investigation comprised of 60 parturient ladies with gestational amenorrhoea of 37-42 weeks and no associated medical illnesses. Collection A consisted of 30 patients with maximum vertical pocket (MVP) $<2 \mathrm{~cm}$ or amniotic fluid index (AFI) $\leq 5 \mathrm{~cm}$. Collection B involved 30 pregnant women having normal amniotic fluid index $>5 \mathrm{~cm}$. The 2 collections were tallied with respect to demographic characteristics and perinatal outcome particularly low birth weight, delivery mode, poor APGAR score, umbilical artery acidosis and meconium staining. Neonatal future stands upon evaluation of levels of lactate found in umbilical cord arterial blood.

Results: According to our findings, commonest mode of childbirth 37 (61.7\%) was Caesarean section. No statistical difference was found between the two aggregations of low weight at birth i.e. 4 (13.3\%). Based on our study, meconium staining at birth was prevalent in $8(13.3 \%)$ of neonates however no meconium aspiration was seen, umbilical artery acidosis was apparent in $27(45 \%)$ and only $5(8.3 \%)$ accounted for poor APGAR scores.

Conclusion: Detrimental pregnancy aftermath and elevated perinatal morbidity correlates with oligohydramnios.

Keywords: Neonatal outcome, Oligohydramnios, Umbilical cord arterial blood lactate levels.

\footnotetext{
This is an Open Access article distributed under the terms of the Creative Commons Attribution License (https://creativecommons.org/licenses/by-nc/4.0/), which permits unrestricted use, distribution, and reproduction in any medium, provided the original work is properly cited.
}

\section{INTRODUCTION}

Amniotic fluid is almost produced exclusively by the foetus and is detected right from the start of the pregnancy. Not only the growth and development but for good sustenance andmaintenance of pregnancy, amniotic fluid plays a crucial part ${ }^{1}$. Its significance is prevalence from the fact that a decrease in its optimum volume gives rise to oligohydramnios. The tendency of oligohydramnios at full-term is $10 \%$ as per AFI volume of $<5 \mathrm{~cm}^{2}$. Oligohydramnios is suspected when the symphisio-fundal height is not corresponding to gestational age. Ultrasonic examination is a reliable way of measuring amniotic fluid volume (AFV). The maximum vertical pocket measurement (MVP) stipulates a largest amniotic fluid pocket excluding umbilical cord or foetal extremities when vertically analysed. Oligohydramnios is characterised by an MVP $<2 \mathrm{~cm}$. Amniotic fluid index can be estimated by making four quadrants of the uterus with the help of linea nigra and umbilicus.

Factors accounting for oligohydramnios comprise of membrane rupture, foetal genital and urinary abnormalities, uteroplacental insufficiency (stunted foetal

Correspondence: Dr Amera Tariq, Classifies Gynaecologist, Pakistan Navel Ship Shifa Karachi Pakistan

Received: 12 Dec 2020; revised received: 18 Jan 2021; accepted: 24 Feb 2021 growth), placental problems and diseases like preeclampsia, which are maternally associated. Majority of the cases are idiopathic. It is in correlation with unfavourable gestational outcomes which may be due to placental insufficiency and umbilical cord compression as per different studies. Either or both of these can lead to increase in caesarean sections, still birth and poor neonatal outcome consequent to foetal heart rate irregularity ${ }^{3,4}$.

This also correlates with meconium staining, low APGAR scores, small for gestational age (SGA) foetus and Neonatal intensive care unit (NICU) admission. Underlying etiology, timing, intensity and duration of oligohydramnios further complicates the pregnancy. Controversy arises regarding the time of delivery. In correlation to normal AFV cases, there is no foetal acidosis and unfavourable neonatal outcome in third trimester in parturient with AFI below $5 \mathrm{~cm}^{5}$. In isolated oligohydramnios cases, delivery is usually conducted at completion of 37 weeks of gestation.

By predicting the level of lactate as well as the value of $\mathrm{pH}$ for the blood in the umbilical cord artery, we can approximate the neonatal outcome. Neonatal hypoxia, a concerning situation can be determined by both prognostics: lactate measurement and $\mathrm{pH}$. It occurs when there is not sufficient oxygen available to 
provide the tissue with energy, leading to anaerobic respiration. Hydrogen ions and lactate elevated levels lead to primarily, respiratory and then consequently, metabolic acidosis ${ }^{6}$. Deficient oxygen supply accompanied with acidosis leads to multiple organ damage so the metabolic state of new-born is of utter significance.

When determining the neonatal state, pHis usually employed more than lactate. However, a massive quantity of blood as well as complex machinery is imperative for $\mathrm{pH}$ calculation instead of lactate levels. On the other hand, the procedure for measuring lactate requires a lesser amount of blood, lower cost and is easier to maintain 7 . The lactate, which is a result of anaerobic respiration, is significantly more important than $\mathrm{pH}$ or of comparable importance indeciding neonatal morbidity ${ }^{8}$. Therefore, our research used the levels of lactate in the umbilical cord's arterial blood to estimate short-lived neonatal outcome. Other variables as well as lactate levels were utilized to analyse both collections i.e. including and excluding oligohydramnios. The objective of the study was to find out the neonatal outcome in women with uncomplicated oligohydramnios at term.

\section{METHODOLOGY}

This research was conducted between the months from March 2020 to October 2020 at Pakistan Naval Ship Shifa Hospital Karachi, department of Obstetrics and Gynaecology. The ethical committee of the aforementioned hospital was consulted for approval (ERC/ 2020/Gynae/17). The sample size $(n=30)$ was found using WHO sample size calculator, with expected rate of caesarean-sections $72.6 \%$ vs $17.5 \%$ between the two collections ${ }^{9}$.

All expecting females without any existing medical illnesses, booked at 20 weeks of pregnancy were included in this research. Willing participants were asked to give informed consent. The exclusion criteria included: women with polyhydramnios (AFI $>18 \mathrm{~cm}$ ), pregnancy induced hypertension $(\mathrm{PIH})$, pre-labour rupture of membranes (PROM), gestational diabetes mellitus (GDM), multifetal pregnancy, foetal growth restriction (FGR), congenital anomalies, post-term gestation, prior record of C-sections, any correlating medical affliction and patients who did not consent to participate. The inclusion criterion for this research was singleton uncomplicated pregnancy with oligohydramnios. All pregnancies were confirmed and dated using last menstrual period (LMP) as well as the ultrasonography of the first trimester. Two collections were formed and the 60 shortlisted parturient participants were divided andgrouped according to ultrasonic findings of isolated oligohydramnios monitored from 28 weeks onward as collection A and the ones without any oligohydramnios development as collection B. The standard for diagnosing oligohydramnios was AFI $\leq 5 \mathrm{~cm}$ or $\mathrm{MVP}<2 \mathrm{~cm}$. Both categories had 30 pregnant women each. Their mode of delivery, between 37-42 weeks pregnancy, was monitored and the consequent neonatal variables were utilised as a contrast in the two collections. Demographic features were corresponded too.

A $20 \mathrm{~cm}$ of double clamped segment of umbilical cord was used as standard procedure for the collection of umbilical cord arterial blood right after the birth. Heparinised syringes were used for the collection of sample that was immediately transferred to the laboratory within 30minutes for lactate levels by an automated analyser machine. Trained staff including midwives and nurses collected the samples. Proformas specifically designed for this study were filled out with APGAR scores, baby weight and the lactate levels for every patient.

Perinatal outcome was figured out as follows:

Acidosis of umbilical artery: Lactate levels being $>3.5 \mathrm{mmol} / \mathrm{l}$, (1.0-3.5) in umbilical cord arterial blood.

Poor APGAR scores: APGAR scores after 5 mins post-delivery being $<5$.

Low birth weight: baby weighing $<2500 \mathrm{~g}$ instantly at birth, as recorded by weight machine.

The two collections, A and B (with and without oligohydramnios), were matched for period of gestation, mode of delivery, presence of meconium in amniotic fluid, umbilical cord acidosis (lactate levels), birth weight and APGAR scores along with demographic profile. Data was interpreted and analysed using IBMSPSS-22. Accordingly, $p$-values and frequencies were estimated. Dis-similarities in the two collections were compared and categorical data with chi-squared and Fisher's exact test. The $p$-value of $\leq 0.05$ was considered significant.

\section{RESULTS}

This study collection constituted 60 pregnant women who gave birth between 37-42 gestational weeks. There was no difference in demographic profiles of the two collections as displayed by table-I.

As per our deductions, the most common childbirth mode was Caesarean section with a statistic of $37(61.7 \%)$. Among collection A, $22(73.3 \%)$ delivered by C-section while among collection B, 15 (50\%) had Csection. Eight $(26.7 \%)$ delivered vaginally in collection 
A and 15 (50\%) had the same mode of delivery in collection B. There was no statistical difference of low weight at birth found between the two collections i.e. $4(13.3 \%)$ in each collection. Twenty six $(86.7 \%)$ in collection A and B had normal birthweight. Overall, our study population showed the following trends: 8 $(13.3 \%)$ neonates were born with meconium staining however no meconium aspiration; $5(16.7 \%)$ in collection A had meconium staining and only $3(10 \%)$ in collection B had meconium. Umbilical artery acidosis $(\mathrm{pH}<7.3$, lactate $>3.5 \mathrm{mmol} / \mathrm{l})$ was prevalent in 27 $(45 \%) p$-value $0.025,18(60 \%)$ in collection A had umbilical artery acidosis evident, while $9(30 \%)$ in collection B showed acidosis. Low APGAR score was in only $5(8.3 \%) p$-value 0.034; 4 (13.3\%) showed low APGAR scores in collection A and only 1 (3.3\%) in collection B had poor APGAR score. There was a great difference in umbilical artery acidosis and APGAR at birth, $p$ value $<0.05$, as visible in table-II. distress and low APGAR scores at 5 minutes is resultant of reduced amniotic fluid quantity as per Chauhan et al ${ }^{11}$. Accumulative caesarean section rates in both collections were $(61.7 \%)$ while collection A (that had oligohydramnios) reported $(73.3 \%)$ in this study.

Golan et al ${ }^{12}$ expressed areduced APGAR score of $(4.6 \%)$ in neonates whereas our study found it to be $8.3 \%$ at low APGAR figures in both categories with collection A showing 13.3\%. Jamal et al ${ }^{13}$ exhibited 9.6\% had low APGAR scores and acidosis of umbilical artery was $11.2 \%$ in oligohydramnios at term. Kahkhaie et al ${ }^{14}$ discovered no significant deviation in the occurrence of meconium in research aggregations, whereas our findings depicted amniotic fluid containing meconium in $13.3 \%$ of neonates; collection A had $16.7 \%$.

Lactate levels in umbilical cord blood are significantly essential after 37 weeks of gestation for deter-

Table-I: Demographic profile of the two collections.

\begin{tabular}{|c|c|c|c|c|}
\hline \multicolumn{2}{|l|}{ Variable } & Collection A & Collection B & $p$-value \\
\hline Age (years) & $\begin{array}{l}\text { Less than } 30 \\
\text { More than } 30\end{array}$ & $\begin{array}{c}25(41.7 \%) \\
5(8.3 \%)\end{array}$ & $\begin{array}{c}21(35 \%) \\
9(15 \%)\end{array}$ & 0.360 \\
\hline Weeks of Gestation & $\begin{array}{l}\text { Less than } 40 \\
\text { More than } 40\end{array}$ & $\begin{array}{c}28(46.7 \%) \\
2(3.3 \%)\end{array}$ & $\begin{array}{c}29(48.3 \%) \\
1(1.7 \%)\end{array}$ & 1.000 \\
\hline Equivalence & Average $\pm \mathrm{SD}$ & $1.45 \pm 1.50$ & $1.83 \pm 1.08$ & 0.263 \\
\hline \multicolumn{5}{|c|}{ Table-II: Comparison of neonatal outcomes in two collections. } \\
\hline \multicolumn{2}{|l|}{ Variables of the Study } & Collection A Findings & Collection B Findings & $p$-value \\
\hline Delivery Method & $\begin{array}{l}\text { Vaginal Delivery } \\
\text { Caesarean Section }\end{array}$ & $\begin{array}{c}8(26.7 \%) \\
22(73.3 \%)\end{array}$ & $\begin{array}{l}15(50 \%) \\
15(50 \%)\end{array}$ & 0.110 \\
\hline Meconium & $\begin{array}{l}\text { Affirmative } \\
\text { Negative }\end{array}$ & $\begin{array}{c}5(16.7 \%) \\
25(83.3 \%)\end{array}$ & $\begin{array}{c}3(10 \%) \\
27(90 \%)\end{array}$ & 0.706 \\
\hline $\begin{array}{l}\text { Umbilical Artery } \\
\text { Acidosis }\end{array}$ & $\begin{array}{l}\text { Affirmative } \\
\text { Negative }\end{array}$ & $\begin{array}{l}18(60 \%) \\
12(40 \%)\end{array}$ & $\begin{array}{c}9(30 \%) \\
21(70 \%)\end{array}$ & 0.025 \\
\hline Poor PGAR Value & $\begin{array}{l}\text { Affirmative } \\
\text { Negative }\end{array}$ & $\begin{array}{c}4(13.3 \%) \\
26(86.7 \%)\end{array}$ & $\begin{array}{c}1(3.3 \%) \\
29(96.7 \%)\end{array}$ & 0.034 \\
\hline $\begin{array}{l}\text { Inadequate Weight at } \\
\text { Time of Birth }\end{array}$ & $\begin{array}{l}\text { Affirmative } \\
\text { Negative }\end{array}$ & $\begin{array}{c}4(13.3 \%) \\
26(86.7 \%)\end{array}$ & $\begin{array}{c}4(13.3 \%) \\
26(86.7 \%) \\
\end{array}$ & 0.114 \\
\hline
\end{tabular}

\section{DISCUSSION}

A healthy normal pregnancy persists with amniotic fluid being its vital component whose adequate amount is not only beneficial for foetal growth but serves as a barrier against injuries, maintains body temperature, fulfils necessary nutritional requirements and provides room for foetal movements ${ }^{1,2,10}$. Low amniotic fluid figures are detrimental for the foetus because they may be correlated with stunted growth, skeletal deformities, pulmonary hypoplasia, declined APGAR values, increased likeliness of caesarean sections, meconium aspiration and NICU admissions ${ }^{3,4}$. Increased rate of C-section (20.2\%) coupled with foetal mining neonatal outcome. In our study $45 \%$ reported elevated lactate levels; $60 \%$ fell into collection A. According to an articleby Tuuli et $a l^{7}$ the results were analogous. Lactate levels accounted for more specificity than $\mathrm{pH}$ in regulating the neonatal morbidity. Lactate majorly formed earlier as a result of anaerobic metabolism, persists longer than $\mathrm{pH}$ and proves more hazardous than $\mathrm{pH}$. Respiratory acidosis is depicted by $\mathrm{pH}$ while metabolic acidosis is shown by high umbilical arterial blood lactate levels which is more harmful. Wiberg et al ${ }^{15}$ reported that umbilical cord arterial blood lactate to be equally good as low $\mathrm{pH}$ for estimating 5 minute APGAR <4. Blood lactate levels in 
artery of umbilical cord determine neonatal prognosis. Suidan et al16 concluded lactate as the major inducer of acidosis in the foetus since the foetus produces lactate on its own. Einikyte et al ${ }^{17}$ discovered that lactate is agreeably as important as $\mathrm{pH}$ in predicting the state of neonates at birth. Umbilical cord arterial lactate levels were found to be raised among neonates with low APGAR scores and more in emergency than elective Caesarean sections ${ }^{18}$. Hina et al ${ }^{19}$ deduced no relation between oligohydramnios and poor neonatal result but unveiled an elevated Caesarean sections rate and elective induction labour as contrasted to term pregnancies without oligohydramnios.

In a study by Tahmina et al, the mean birth weights among the two study collections were found to be important statistically $(p=0.0017)$, while our study depicted no prominent difference among the research categories ${ }^{20}$. There is strong association of meconium staining of amniotic fluid and oligohydramnios ${ }^{21}$. This is comparable to our research. Another study depicted more incidence of caesarean section, haemorrhage and fetal malposition in women with oligohydramnios than those having normal AFV. It also revealed higher occurrence of intrauterine deaths, neonatal demise and low birth weight 22,8 . Our findings were a higher rate of operative delivery, occurrence of meconium, umbilical arterial blood acidosis and low APGAR scores in pregnant women with oligohydramnios. Another study showed umbilical cord arterial blood lactate dehydrogenase levels were a better predictor of neonatal prognosis when compared with $\mathrm{pH}$ values in hypertensive patients 23,24 .

\section{CONCLUSION}

Oligohydramnios is the major cause of adverse pregnancy and perinatal outcome. Proper analysis of amniotic fluid is a vital step for a good antenatal diagnosis. Unfortunate neonatal results can be avoided by close observation of pregnant women with oligohydramnios. Umbilical cord arterial blood lactate levels anticipate neonatal outcomes markedly, proving this marker pivotalin assessment of acidosis in new-borns.

\section{CONFLICT OF INTEREST}

This study has no conflict of interest to be declared by any author.

\section{REFERENCES}

1. Brace RA. Physiology of amniotic fluid volume regulation. Clin Obstet Gynecol 1997; 40(2): 280-89.

2. Locatelli A, Zagarella A, Toso L, Assi F, Ghidini A, Biffi A. Serial assessment of amniotic fluid index in uncomplicated term preg- nancies: prognostic value of amniotic fluid reduction. J Matern Fetal Neonatal Med 2004; 15(4): 233-36.

3. Sarno AP, Ahn MO. Intrapartum amniotic fluid volume at term. Association of ruptured membranes, oligohydramnios and increased foetal risk. J Reprod Med 1990; 35(7): 719-23.

4. Alchalabi HA, Obeidat BR, Jallad MF, Khader YS. Induction of labour and perinatal outcome: The impact of the amniotic fluid index. Eur J Obstet Gynecol Reprod Biol 2006; 129(2): 124-27.

5. Ashwal E, Hiersch L, Melamed N. The association between isolated oligohydramnios at term and pregnancy outcome. Arch Gynecol Obstet 2014; 290: 875-81.

6. Tuuli MG, Stout MJ, Shanks A, Odibo AO, Macones GA, Cahill AG. Umbilical cord arterial lactate compared with $\mathrm{pH}$ for predicting neonatal morbidity at term. Obstet Gynecol 2014; 124(4): 756-61.

7. Allanson ER, Waqar T, White CRH, Tunçalp Ö, Dickinson JE. Umbilical lactate as a measure of acidosis and predictor of neonatal risk: a systematic review. Intl J Obs Gynae 2017; 124(4): 584-94.

8. Fiala $\mathrm{M}$, Baumert $\mathrm{M}$, Surmiak $\mathrm{P}$, Walencka Z, Sodowska P. Umbilical markers of perinatal hypoxia. Ginekol Pol 2016; 87(3): 200-04.

9. Siraj A, Baqai S, Naseer S, Raja A. The effect of uncomplicated oligohydramnios on perinatal outcome. Pak Armed Forces Med J 2016; 66(3): 333-36.

10. Brace RA, Wolf EJ. Normal amniotic fluid volume changes throughout pregnancy. Am J Obstet Gynecol 1989; 161(2): 382-88.

11. Chauhan SP, Sanderson M, Hendrix NW, Magann EF, Devoe LD. Perinatal outcome and amniotic fluid index in the antepartum and intrapartum periods: A meta-analysis. Am J Obstet Gynecol 1999; 181(6): 1473-78.

12. Golan A, Lin G, Evron S, Arieli S, Niv D, David MP. Oligohydramnios: maternal complications and foetal outcome in 145 cases. Gynecol Obstet Invest 1994; 37(2): 91-95.

13. Jamal A, Kazemi M, Marsoosi V, Eslamian L. Adverse perinatal outcomes in borderline amniotic fluid index. Int J Reprod Biomed 2016; 14(11): 705-08.

14. Rezaie Kahkhaie K, Keikha F, Abdollahimohammad A, Salehin S. Perinatal outcome after diagnosis of oligohydramnios at term. Iran Red Crescent Med J 2014; 16(5): e11772.

15. Wiberg N, Källén K, Herbst A, Olofsson P. Relation between umbilical cord blood $\mathrm{pH}$, base deficit, lactate, 5-minute Apgar score and development of hypoxic ischemic encephalopathy. Acta Obstet Gynecol Scand 2010; 89(10): 1263-69.

16. Suidan JS, Antoine C, Silverman F, Lustig ID, Wasserman JF, Young BK. Human maternal-foetal lactate relationships. J Perinat Med 1984; 12 (1984): 211-17.

17. Einikyte R, Snieckuviene V, Ramasauskaite D, Panaviene J, Paliulyte V, Opolskiene G, et al. The comparison of umbilical cord arterial blood lactate and $\mathrm{pH}$ values for predicting shortterm neonatal outcomes. Taiwan J Obstet Gynecol 2017; 56(6): 745-49.

18. Revathy Natesan S. Routine measurements of cord arterial blood lactate levels in infants delivering at term and prediction of neonatal outcome. Med J Malaysia 2016; 71(3): 131-33.

19. Ahmad H, Munim S. Isolated oligohydramnios is not an indicator for adverse perinatal outcome. J Pak Med Assoc 2009; 59(10): 691-94.

20. Tahmina S, Prakash S, Daniel M. Maternal and perinatal outcomes of induction of labour in oligohydramnios at term-a retrospective cohort study. J Matern Fetal Neonatal Med 2020; 33(13): 2190-94. 
21. Rathod S, Samal SK. Evaluation of maternal and perinatal outcomes of induction in borderline oligohydramnios at term. J Clin Diagn Res 2017; 11(9): QC05-07.

22. Figueroa L, Mc-Clure EM, Swanson J, Nathan R, Garces AL, Moore JL, et al. Oligohydramnios: a prospective study of fetal, neonatal and maternal outcomes in low-middle income countries. Reprod Health 2020; 17(1): 192-6.
23. Kumar N, Yadav A. Role of umbilical cord arterial $\mathrm{pH}$ and lactate in newborn assessment of term antenatal women with hypertensive disorders of pregnancy. Clin Epidemiol Glob Heal 2020; 8(3): 927-33.

24. Taneja A, Arora K, Chopra I, Naik SS. Pregnancy Outcomes in Isolated Oligohydramnios during Second Trimester: A Case Series. J Clin Diagn Res 2017; 11(8): QR01-02. 